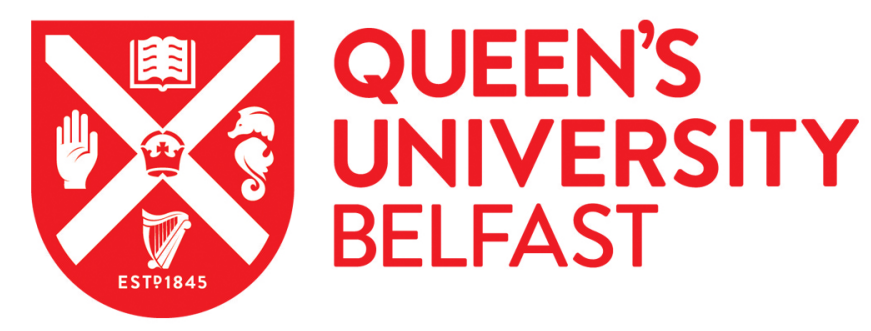

\title{
Hydrogel-forming microneedle arrays made from light-responsive materials for on-demand transdermal drug delivery
}

Hardy, J. G., Larrañeta, E., Donnelly, R. F., McGoldrick, N., Migalska, K., McCrudden, M. T. C., Irwin, N. J.,

Donnelly, L., \& McCoy, C. P. (2016). Hydrogel-forming microneedle arrays made from light-responsive materials for on-demand transdermal drug delivery. Molecular Pharmaceutics, 13(3), 907-914.

https://doi.org/10.1021/acs.molpharmaceut.5b00807

Published in:

Molecular Pharmaceutics

Document Version:

Peer reviewed version

Queen's University Belfast - Research Portal:

Link to publication record in Queen's University Belfast Research Portal

\section{Publisher rights}

(C) 2016 American Chemical Society

This document is the Accepted Manuscript version of a Published Work that appeared in final form in Molecular Pharmaceutics, copyright ( American Chemical Society after peer review and technical editing by the publisher.

To access the final edited and published work see http://pubs.acs.org/doi/10.1021/acs.molpharmaceut.5b00807

\section{General rights}

Copyright for the publications made accessible via the Queen's University Belfast Research Portal is retained by the author(s) and / or other copyright owners and it is a condition of accessing these publications that users recognise and abide by the legal requirements associated with these rights.

Take down policy

The Research Portal is Queen's institutional repository that provides access to Queen's research output. Every effort has been made to ensure that content in the Research Portal does not infringe any person's rights, or applicable UK laws. If you discover content in the Research Portal that you believe breaches copyright or violates any law, please contact openaccess@qub.ac.uk. 
Hydrogel-forming microneedle arrays made from stimuli-responsive materials for ondemand drug delivery.

John G. Hardy*, Eneko Larrañeta*, Ryan F. Donnelly, Niamh McGoldrick, Katarzyna Migalska, Maelíosa T.C. McCrudden, Louise Donnelly and Colin P. McCoy**.

School of Pharmacy, Queens University Belfast, Medical Biology Centre, 97 Lisburn Road, Belfast BT9 7BL, Northern Ireland, UK.

*First two authors contributed equally

**Corresponding author

Professor Colin P. McCoy

Chair in Biomaterials Chemistry

School of Pharmacy,

Queens University Belfast,

Medical Biology Centre,

97 Lisburn Road,

Belfast

BT9 7BL, UK

Tel: +44 (0) 2890972081

Fax: +44 (0) 2890247794

Email: c.mccoy@qub.ac.uk 


\begin{abstract}
We describe, for the first time, stimuli-responsive hydrogel-forming microneedle (MN) arrays that enable delivery of a clinically-relevant model drug (ibuprofen) upon application of light. MN arrays where prepared using a polymer prepared from 2-hydroxyethyl methacrylate (HEMA) and ethylene glycol dimethacrylate (EGDMA) by micromolding. The obtained MN arrays showed good mechanical properties. The system was loaded with up to $5 \%(\mathrm{w} / \mathrm{w})$ ibuprofen included in a light-responsive 3,5-dimethoxybenzoin conjugate. Raman spectroscopy confirmed the presence of the conjugate inside the polymeric $\mathrm{MN}$ matrix. In vitro, this system was able to deliver up to three doses of $50 \mathrm{mg}$ of ibuprofen upon application of an optical trigger over a prolonged period of time (up to 160 hours). This makes the system appealing as a controlled release system for prolonged periods of time. We believe that this technology has potential for use in "on-demand" delivery of a wide range of drugs in a variety of applications relevant to enhanced patient care.
\end{abstract}

Keywords: Microneedle, hydrogel, stimuli-responsive, light-triggered 


\section{Graphical Abstract}

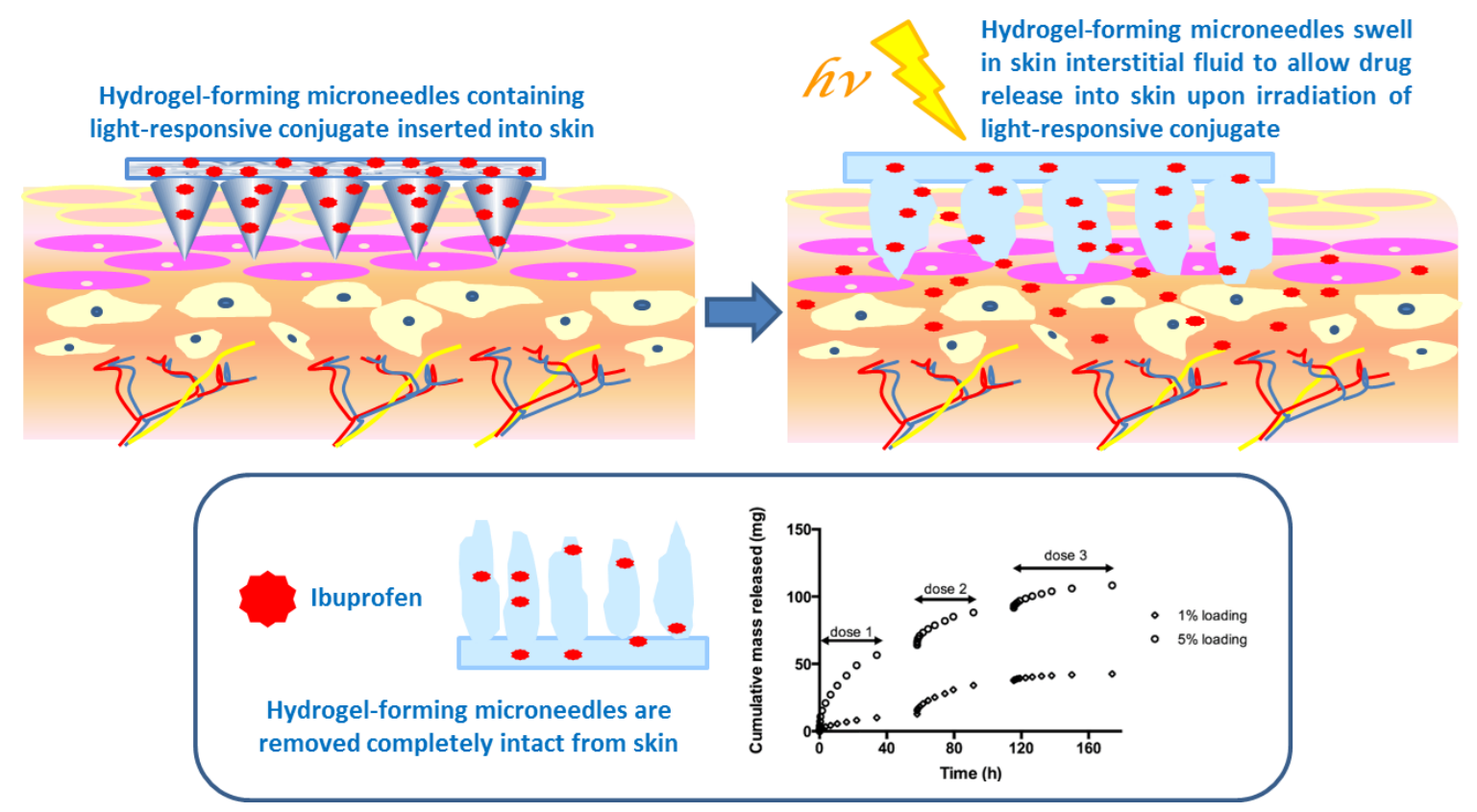




\section{Introduction}

Microneedle arrays (MN) are minimally-invasive devices that painlessly, and without drawing blood, penetrate the skin's stratum corneum barrier (1-8). MN have been extensively investigated in recent years for enhanced transdermal and intradermal delivery of vaccines and drug substances $(1,9-14)$. MN have generally been employed for delivery of bolus doses in relatively short periods of times, in contrast to conventional transdermal patches, which are used for sustained drug delivery, often over several days. Nevertheless we have recently described hydrogel-forming $\mathrm{MN}$ that rapidly imbibe skin interstitial fluid upon insertion to form discrete in situ hydrogel bulbs, which then control drug administration. In this case, release from the swollen $\mathrm{MN}$ is determined by the crosslink density of the swollen hydrogel network formed and delivery over several days is possible (15-20). In other work, MN have been combined with iontophoresis (the application of a small electric current, typically $\leq 0.5$ $\mathrm{mA} / \mathrm{cm}^{2}$, to drive ionic and polar molecules across the skin) to facilitate enhanced rates of drug delivery across skin pre-punctured with MN (21-25). Most studies involve pre-treating skin with MN puncture and then application of an iontophoretic patch, which is not particularly convenient. However, iontophoresis set-ups (electrodes, power source, controller) are typically complex, expensive and quite bulky. Accordingly, very few iontophoretic patches are on the market currently (13), with those that are being very much niche products. As a result, it is difficult to imagine even more complex $\mathrm{MN}$-iontophoresis combination products being a priority for development by industry. If "on-demand" or pulsatile delivery from a MN system is to be developed into a patient-friendly, low cost product, an external stimulus for drug delivery from an otherwise benign delivery system would be very useful. In order to address the lack of "on demand" transdermal delivery systems some research groups are starting to develop MN-based stimulus responsive delivery systems (26-28). 
In combination with our previous works dealing developing hydrogel-forming $\mathrm{MN}$ arrays we have previously developed materials impregnated with light-responsive drug conjugates (29, 30). Such conjugates are able to latently retain drug until light is applied, and the dose of drug liberated can be precisely controlled by the total energy applied, in line with the kinetics of photolysis of the conjugate. Therefore in this study, we investigated the combination of these two technologies to develop hydrogel-based MN arrays containing a light-responsive drug conjugate for light-triggered transdermal drug delivery.

\section{Materials and Methods}

\section{Chemicals}

Ibuprofen, dichloromethane, dimethylaminopyridine (DMAP), dicyclohexylcarboiimide (DCC), acetone, hexane, 2-hydroxyethylmethacrylate, ethylene glycol dimethacrylate, benzyl peroxide, phosphate buffer tablets, silica and silica plates were all obtained from Aldrich, Gillingham, Dorset, UK. Dichloromethane (DCM), ethanol (EtOH), ethyl acetate (EtOAc), hexane, acetonitrile and acetone were all obtained from BDH Laboratories, Poole, Dorset, UK. All other chemicals used were of analytical reagent grade.

\section{Synthesis and characterisation of light-responsive ibuprofen conjugates}

2-(3,5-dimethoxyphenyl)-2-hydroxy-1-phenylethanone (3,5-dimethoxybenzoin, $1.00 \mathrm{~g}, 3.67$ $\mathrm{mmol})$ and ibuprofen $(0.76 \mathrm{~g}, 3.67 \mathrm{mmol})$ were added to dried dichloromethane $(15 \mathrm{ml})$, to which 4-dimethylaminopyridine (DMAP) $(0.03 \mathrm{~g}, 0.2 \mathrm{mmol})$ was added. The solution temperature was maintained at $0{ }^{\circ} \mathrm{C}$ using an ice bath. $\mathrm{N}, \mathrm{N}$-dicyclohexylcarbodiimide (DCC) (0.76 g, $3.67 \mathrm{mmol})$ was added to the solution. The solution was then stirred for $24 \mathrm{hrs}$ at $0{ }^{\circ} \mathrm{C}$, 
with a drying tube to prevent any water entering the solution. After $24 \mathrm{hrs}$ the dicyclohexylurea (DCU) by-product was removed by filtration and the volatiles removed under vacuum. The product was purified by flash chromatography on a silica gel column using ethyl acetate:hexane $(3: 2 \mathrm{v} / \mathrm{v})$ as the eluent. The product, a light-responsive ibuprofen conjugate was a viscous yellow oil $(1.29 \mathrm{~g}, 73 \%, 2.80 \mathrm{mmol}) . \delta\left(\mathrm{CDCl}_{3}\right)$ : 7.84-7.87 $\left(\mathrm{Ar}-1-2-\mathrm{H}_{9}, \mathrm{~s}, \mathrm{dd}, \mathrm{d}, J=6.25 \mathrm{~Hz}\right)$, 7.42 ( Ar-1-2 - $\mathrm{H}_{11}, \mathrm{~m}$ ), 7.30-7.34 (Ar-1- $\mathrm{H}_{10}, \mathrm{~m}$ ), 7.20-7.25 ( Ar-3- $\left.\mathrm{H}_{5}, m\right)$, 7.14-7.19( Ar-3, H3, dd, $J=5.0), 6.75\left(\mathrm{H}_{14}, \mathrm{~d}, J=1.9 \mathrm{~Hz}\right), 6.5-6.55\left(\mathrm{Ar}-1-2-\mathrm{H}_{8}, \mathrm{dd}, J=1.0 \mathrm{~Hz}\right), 6.32-6.39$ ( Ar-2- $\left.\mathrm{H}_{13}, \mathrm{~m}\right), 4.12-4.18\left(\mathrm{H}_{7}-\mathrm{CH}, \mathrm{m}\right), 3.71-3.79\left(\mathrm{Ar}-2-\mathrm{H}_{12}-\mathrm{OCH}_{3} \mathrm{~d}, J=1.0 \mathrm{~Hz}\right), 2.41-2.48$ $\left(\mathrm{H}_{4}-\mathrm{CH}_{2}, \mathrm{~m}\right), 1.82-1.87\left(\mathrm{H}_{2}-\mathrm{CH}, \mathrm{m}\right), 1.48-1.59\left(\mathrm{H}_{6}-\mathrm{CH}_{3}, \mathrm{~m}\right), 0.75-0.82\left(\mathrm{H}_{1}-\mathrm{CH}_{3}, \mathrm{~m} J\right.$ $=5.0 \mathrm{~Hz}) . \mathrm{IR} v_{\max } / \mathrm{cm}^{-1}(\mathrm{KBr}): 2945$ methine group $(\mathrm{CH}), 1670$ ketone group $(\mathrm{R}-\mathrm{C}=\mathrm{O}-\mathrm{R}), 1730$ ester (R-C=O-OR). m/z(\%): $461.2\left(\mathrm{M}^{+}, 59\right), 255.3$ (434), 920.8 (100), 919.3 (24), 942.9 (12), 413.4 (9), 212.3 (3), 227.3 (8), 256.3(7). Elemental analysis: $\mathrm{C}_{29} \mathrm{H}_{32} \mathrm{O}_{5}$ requires: $\mathrm{C} 75.63 \%, \mathrm{H}$ 7\%, O 17.37\%. Found: C 75.62\%, H 7.01\%, O $17.35 \%$.

\section{Preparation and physicochemical characterisation of drug loaded MN arrays}

Laser-engineered silicone micromould templates were used in micromoulding of MN arrays and were microfabricated using a previously-reported approach (31). The moulds were composed of $9(3 \times 3)$ or $121(11 \times 11)$ needles perpendicular to the base, of conical shape and $600 \mu \mathrm{m}$ in height, with base width of $300 \mu \mathrm{m}$ and interspacing of $300 \mu \mathrm{m}$. 2-hydroxyethyl methacrylate (HEMA, 98.6\% w/w), ethylene glycol dimethacrylate (EGDMA, 1\% w/w) and $\mathrm{BPO}(0.4 \%, \mathrm{w} / \mathrm{w})$ and the light-responsive ibuprofen conjugate (1 to $5 \% \mathrm{w} / \mathrm{w}$ ) were mixed with a magnetic stirrer until all of initiator was dissolved. MN arrays were prepared only with the HEMA polymer to evaluate the ability of this type of polymer to form MN. For this purpose MN moulds were filled to the top with the HEMA, EGDMA and BPO solution (0.5 g), 
centrifuged at $3000 \mathrm{rpm}$, refilled to replace part of the evaporated solution and placed in the oven at $90{ }^{\circ} \mathrm{C}$ for two hours.

Additionally swelling kinetics of hydrogels obtained by crosslinking HEMA (pHEMA) was evaluated. Hydrogels squares $(0.81 \pm 0.05 \mathrm{~g} ; 12.6 \pm 0.4 \times 16.6 \pm 0.4 \times 5.2 \pm 0.2 \mathrm{~mm})$ were weighed as $\mathrm{m}_{\mathrm{o}}$ and then swollen in $50 \mathrm{~mL}$ of $\mathrm{pH} 7$ phosphate buffer solution (PBS) for $24 \mathrm{~h}$ at room temperature. At regular intervals, the films were removed, dried with filter paper to eliminate excess surface water and weighed as $\mathrm{m}_{\mathrm{t}}$ (hydrogels). The percentage swelling, was calculated, respectively, by using Equation 1.

$\%$ Swelling $=100 \times\left(\mathrm{m}_{\mathrm{t}}-\mathrm{m}_{\mathrm{o}}\right) / \mathrm{m}_{\mathrm{o}}$

In order to prepare $\mathrm{MN}$ for mechanical testing and drug delivery, the polymer mixture was poured into the laser drilled $3 \times 3$ or $11 \times 11$ silicon moulds at weight of $0.5 \mathrm{~g}$ per array, the moulds were then centrifuged for 10 minutes to remove any air bubbles at $3000 \mathrm{rpm}$ and then placed in the oven at $90{ }^{\circ} \mathrm{C}$ for two hours, the $\mathrm{MN}$ moulds were removed from the oven, allowed to cool and then the MNs were removed from the moulds. The "sidewalls" formed by the moulding process were removed using a heated blade, as described previously (31). It is important that these moulds remain covered to protect them from light. Uniformity with regards to height and width of each batch of MN arrays was examined by a digital microscope under the magnification 180x, using the ruler function of the microscope software.

Raman spectroscopy was carried out using on hydrated $1 \mathrm{~cm}^{2}$ squares of pHEMA and on pHEMA incorporated with light responsive conjugate. Raman spectra and maps were obtained using an Avalon Instruments Raman Station R3 coupled to an Olympus BX 50 microscope. 
Samples were placed on a microscope slide and Raman scattered light from a 785nm laser operating at $300 \mathrm{~mW}$ focused on the surface of the sample was collected between $400-3200 \mathrm{~cm}^{-}$

${ }^{1}$ at a resolution of $2 \mathrm{~cm}^{-1}$, and with a total collection time of $120 \mathrm{~s}$.

\section{MN characterisation}

Formed MN arrays were visualised using a Keyence VHX-700F Digital Microscope equipped with a VH-Z20R lens (Keyence, Osaka, Japan), which allows automatic sizing of multiple MN, facilitating quality control in terms of efficiency and reproducibility of $\mathrm{MN}$ formation within and between individual arrays. Additionally needle dimensions where evaluated using an Aigo Digital Viewer GE-5 (Aigo, Beijing, China). MN arrays were also subjected to compression tests in order to ascertain their mechanical strength. Mechanical properties were evaluated using a TA-XT2 Texture Analyser (Stable Microsystems, Haslemere, UK) in compression mode, as described previously [16]. MN arrays were visualised before and after application of the compression load using a desktop light microscope (GXMGE-5 digital microscope, Laboratory Analysis Ltd., Devon, UK).

\section{In vitro drug delivery studies}

These experiments were performed with a system employing Franz-diffusion cells. pHEMA MNs with $1 \%$ or $5 \%$ loading of the photoresponsive drug conjugate were manufactured as detailed in MN preparation methodology. The MNs were then punctured through a synthetic skin membrane. At this stage they were visualised under a microscope to check no damage had occurred to the MNs and that they had all punctured through the synthetic membrane. The MN arrays were then irradiated with a $15 \mathrm{~W} \mathrm{Hg}$ discharge UV lamp source at $365 \mathrm{~nm}$ at a fixed distance of $10 \mathrm{~mm}$ from the light source for $1 \mathrm{hr}$. At the $1 \mathrm{hr}$ time point they were then attached to the receptor compartment of the Franz-diffusion cells, and the receptor phase volume was 
recorded. The surface area of the MN array exposed to the receptor compartment was $2.96 \mathrm{~cm}^{2}$. The receptor medium was PBS. A measured volume of receptor solution (3 ml) was added to each receptor compartment with a magnetic stirring bead. The diffusion cells were placed on a magnetic stirring plate in a water bath kept at $36{ }^{\circ} \mathrm{C}$, resulting in skin temperature at the membrane surface of approximately $32{ }^{\circ} \mathrm{C}$ during the experiment. Using a needle, samples (3 ml) were collected from the receptor compartment at defined time intervals and were immediately refilled by fresh receptor solution. These samples were then assayed by UV spectroscopy at a wavelength of $365 \mathrm{~nm}$. The experiment included 3 replicates of pHEMA arrays (3x3 and 11x11 MN arrays) loaded with the photoresponsive drug conjugate and 3 replicates of pHEMA arrays without any photoresponsive drug conjugate as the experimental control. Repeated sampling occurred over a $24 \mathrm{hr}$ time frame, with repeated 1hour irradiations.

\section{Statistical analysis}

Where appropriate, data was analyzed using a one-way ANOVA with post-hoc comparisons performed using the Tukey-Kramer test. In all cases, $p<0.05$ denoted significance. Statistical Package for the Social Sciences, SPSS 18.0 version 2.0 (SPSS, Inc., Chicago, IL, USA), was used for all analyses.

\section{Results}

The light-responsive ibuprofen conjugate was prepared by the Steglich esterification of the carboxylic acid of ibuprofen and the alcohol of 3,5-dimethoxybenzoin in dichloromethane in the presence of DCC and DMAP (Figure 1A); silica column chromatography afforded the analytically pure conjugate (as determined by NMR, infrared spectroscopy and mass spectrometry) in $73 \%$ yield. Figure 1B shows also the scheme of light triggered release of 
ibuprofen when the conjugate is irradiated under certain type of light yielding the free drug and 2-phenyl-5,7-dimethoxybenzofuran $(29,30,32)$.

A

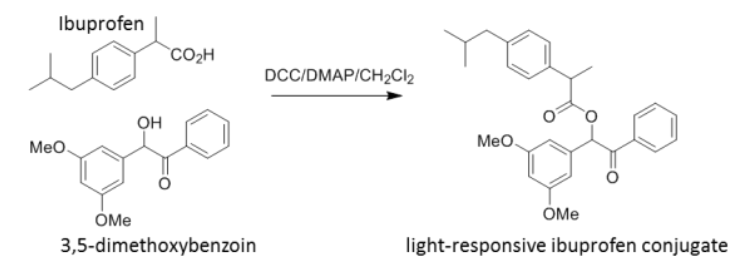

B

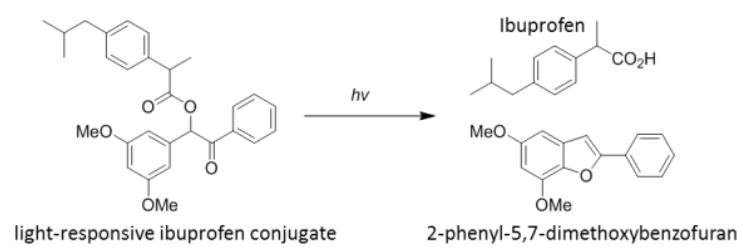

Figure 1. Synthesis of light-responsive ibuprofen conjugate (A). Light-triggered release of ibuprofen from the conjugate (B).

The manufacture of novel pHEMA MNs with varying percentages of EGDMA (1\% to 5\%), yet higher EGDMA loadings yielded mechanically unstable gels. We found that the pHEMA MNs with the $1 \%$ EGDMA composition were more uniform with regards to height and width, and displayed more reproducibility than batches of MN arrays with 5\% EGDMA, therefore we focused on pHEMA MN arrays incorporating 1\% EGDMA (see supporting information Figure S1). MN arrays prepared using the selected polymer were evaluated using microscopy (Figure 2). All the needles were properly formed and the $3 \mathrm{D}$ reconstruction of the surface of some needles in an 11x11 arrays showed that the needle heights of around $450 \mu \mathrm{m}$. 
Additionally, the swelling kinetic of the selected pHEMA hydrogel was evaluated (Figure 3). As it can be seen the water uptake is continuous during the first hours reaching a $35 \%$ of swelling after 24 hours.
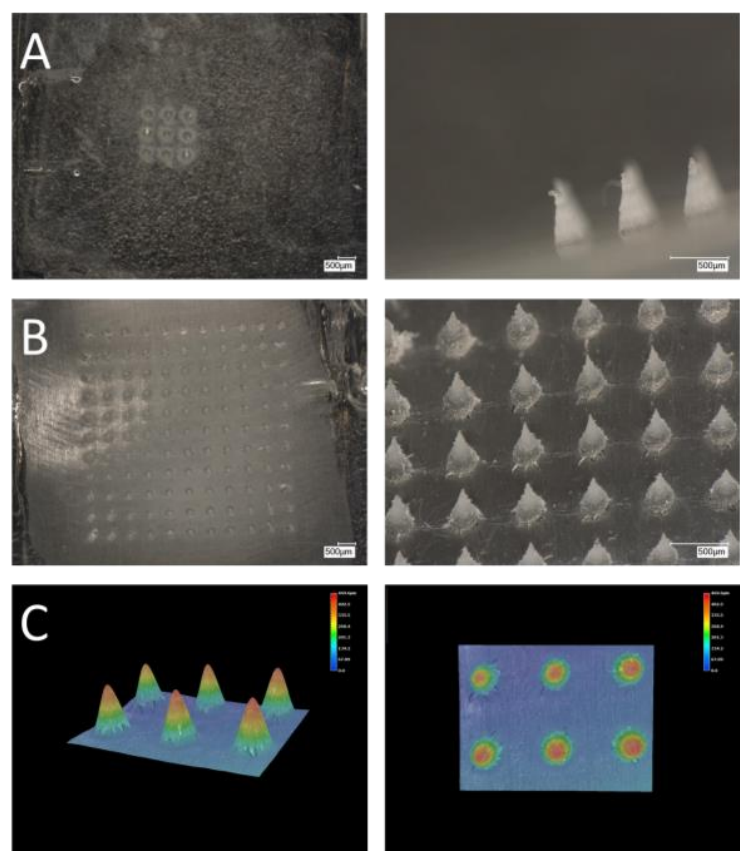

Figure 2. Microscopy images of PHEMA MNs containing 1\% EGDMA prepared using 3x3 (A) and 11x11 (B) moulds. 3D reconstruction of 6 needles from 11x11 pHEMA MN array (C). The 3D pictures without colour scale can be found on the Supplementary Information Figure $\mathrm{S} 2$. 


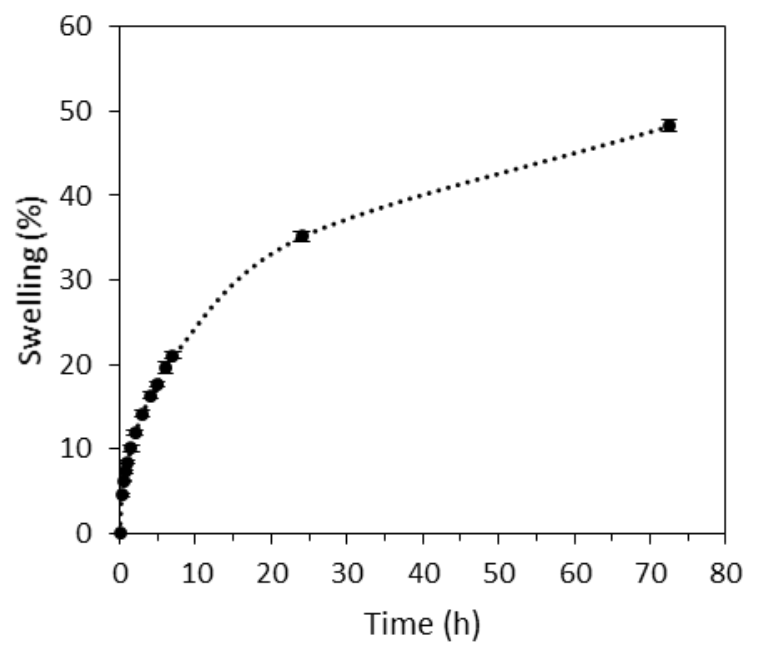

Figure 3. Swelling curve for pHEMA hydrogel containing $1 \%$ of EGDMA in PBS. Data are shown as mean \pm standard deviation of 3 replicates.

In order to ascertain the presence of the light responsive conjugate in the pHEMA network, Raman spectroscopy was used. The spectrum of pHEMA with $1 \%$ of the light responsive conjugate incorporated into the matrix (Figure 4) showed peaks at $990 \mathrm{~cm}^{-1}, 992 \mathrm{~cm}^{-1}, 1596$ $\mathrm{cm}^{-1}$ and $1622 \mathrm{~cm}^{-1}$ that confirm the presence of the light responsive conjugate. The $990 \mathrm{~cm}^{-1}$ and $992 \mathrm{~cm}^{-1}$ peaks are attributed to the presence of the ester bond $(\mathrm{C}-\mathrm{O}-\mathrm{C})$ and the peaks at $1596 \mathrm{~cm}^{-1}$ and $1622 \mathrm{~cm}^{-1}$ are due to the aromatic groups which are present in the conjugate (33). 


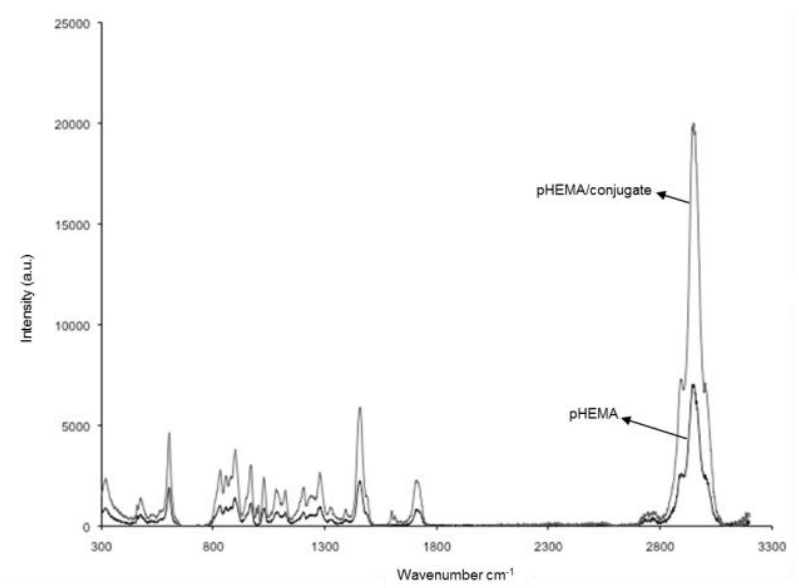

Figure 4. Raman spectra of pHEMA and pHEMA with $1 \%$ of the light responsive conjugate incorporated into the matrix.

Mechanical properties of the materials containing the light responsible conjugate were evaluated. We observed that the presence of the light responsive conjugate within the hydrogels resulted in slight modifications to the bulk mechanical properties of the gels when exposed to tensile stress (see supporting information Table S1), however ANOVA showed these different results to be statistically insignificant. Furthermore, the heights and widths distribution of the MNs seem to be independent of the photoresponsive conjugate concentration (Table 1). Furthermore, it is noticeable that the obtained needles were shorter than expected (ca. $425 \mu \mathrm{m}$ instead of $600 \mu \mathrm{m}$ ). This behaviour has not been obtained in our group before in the production of Gantrez ${ }^{\circledR}$ hydrogel-forming MN arrays $(16,19)$. Nevertheless the manufacturing process was totally different and in this case it can be due to the different crosslinking process. 
Table 1. Morphology of microneedles prepared from pHEMA formulations containing increasing loadings of light responsive conjugate. Data are shown as means \pm standard deviation of eight replicates.

\begin{tabular}{ccc}
\hline MN arrays & Height $(\mu \mathrm{m})$ & Width at base $(\mu \mathrm{m})$ \\
\hline $1 \%$ light responsive & $424.12 \pm 1.04$ & $313.25 \pm 1.5$ \\
conjugate & & $315.00 \pm 1.9$ \\
$5 \%$ light responsive & $425.03 \pm 2.2$ & \\
conjugate & & \\
\end{tabular}

If used as transdermal drug delivery patches, the mechanical properties of the $\mathrm{MN}$ arrays under compression are of greater importance, consequently, the strength of the different $\mathrm{MN}$ formulations was determined by calculating the force required to fracture the microneedles (Figure 5). Three different hydrogel formulations (pHEMA, pHEMA with $1 \%$ light responsive conjugate, and pHEMA with 5\% light responsive conjugate) were studied with a range of applied forces $(0.05 \mathrm{~N}$ to $0.5 \mathrm{~N}$ per needle). Exposure of the hydrogel-based $\mathrm{MN}$ to compression results in their deformation, yet there was no significant difference in the degree of deformation between the three formulations. Indeed, exposure to the minimal applied force $(0.05 \mathrm{~N}$ per needle) resulted in approximately $2 \%$ average reduction in the height, whereas under the maximum load ( $0.5 \mathrm{~N}$ per needle), MN height was reduced by approximately $8.3 \%$. The significance of the compression experiments can only be properly evaluated when compared with the corresponding insertion forces (34). Recently, Larrañeta et al. showed that the maximum average force that a group of human volunteers exerts when applying MNs was $32 \mathrm{~N}$ (35). In another research work, Lutton et al. reported that when inserting other type of 
hydrogel-forming MN arrays (32x32 needles; $600 \mu \mathrm{m}$ of needle length) in a skin simulant using this force $(0.16 \mathrm{~N} /$ needle) the needle height reduction was ca. 3\% (36). These values are consistent with those obtained in this work.

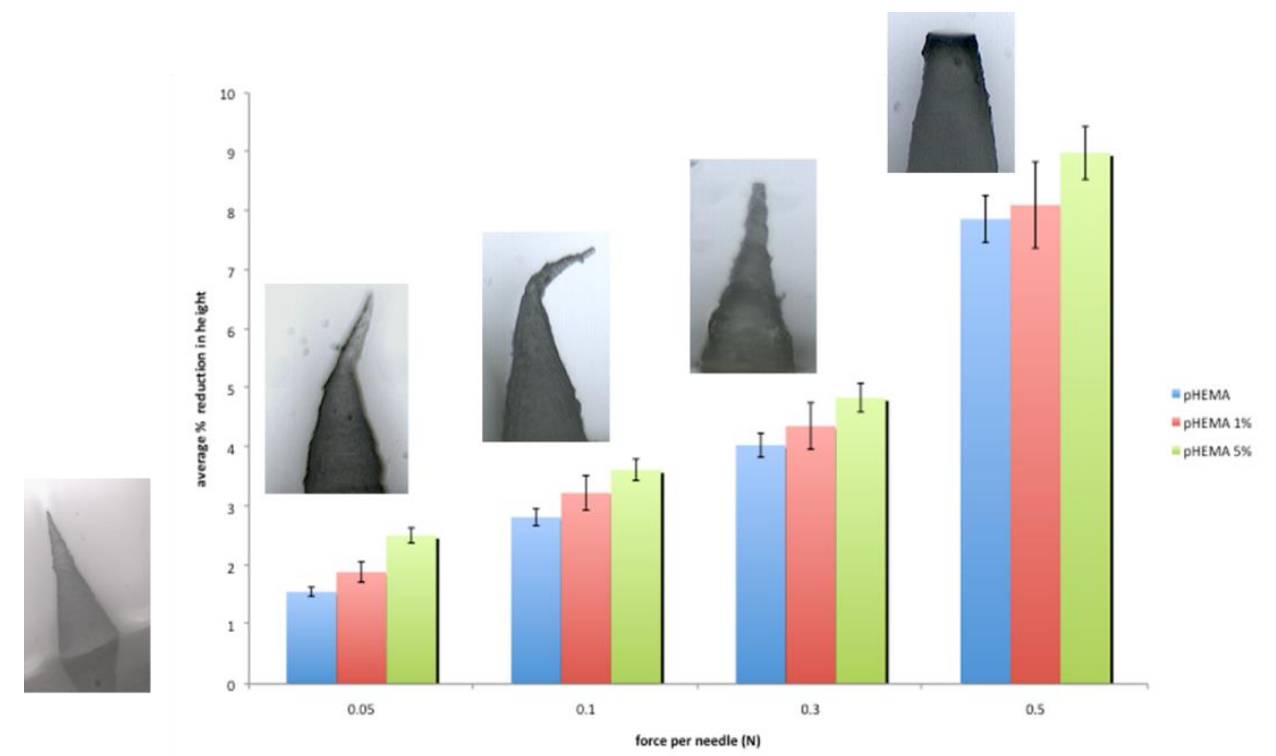

Figure 5. Images of different $\mathrm{MN}$ arrays after $0 \mathrm{~N}, 0.05 \mathrm{~N}, 0.1 \mathrm{~N}, 0.3 \mathrm{~N}$ and $0.5 \mathrm{~N}$ have been applied (force per needle). A graph depicting the average \% reduction in height of three different type of pHEMA microneedle array formulations (pHEMA, pHEMA loaded with 1\% conjugate 1 and pHEMA loaded with $5 \%$ ) as different forces ranging from $0.05 \mathrm{~N}$ to $0.5 \mathrm{~N}$ are applied to the microneedle arrays. Data are shown as mean \pm standard deviation of five replicates.

To demonstrate the ability of these hydrogel-based MNs to deliver a clinically relevant model therapeutic agent (ibuprofen) in vitro, two different $\mathrm{MN}$ array designs ( $3 \times 3$ and 11x11 arrays), and two different loadings of the light responsive conjugate $(1 \%$ and $5 \%)$ were studied. The drug release profiles of a $3 \times 3 \mathrm{MN}$ arrays loaded with the light responsive conjugate after 
successive periods of 1 hour of irradiation (Figure 6A) show that the majority of drug is released after the first two periods of irradiation, with a significant reduction of ibuprofen release after the third irradiation. Ibuprofen release from $3 \times 3 \mathrm{MN}$ arrays triggered by 3 cycles of exposure to light for 1 hour followed by 5 hours of rest (Figure 6B) logically shows that hydrogels with higher loadings of the conjugate contained slightly more residual conjugate after the same duration of irradiation, suggesting their suitability for applications requiring prolonged exposure to a specific drug. Similar trends in ibuprofen release profiles were obtained from the $11 \times 11 \mathrm{MN}$ arrays (Figure 6C). The cumulative fraction of ibuprofen released from $3 \times 3$ and $11 \times 11$ arrays after successive periods of 1 hour exposure to light without a rest period (Figure 6D), show that drug release from the 11x11 arrays are greater than from $3 \times 3$ arrays, because the surface areas of the $11 \times 11$ arrays are greater, thereby enabling faster diffusion of the drug from the surface of the microneedle arrays.
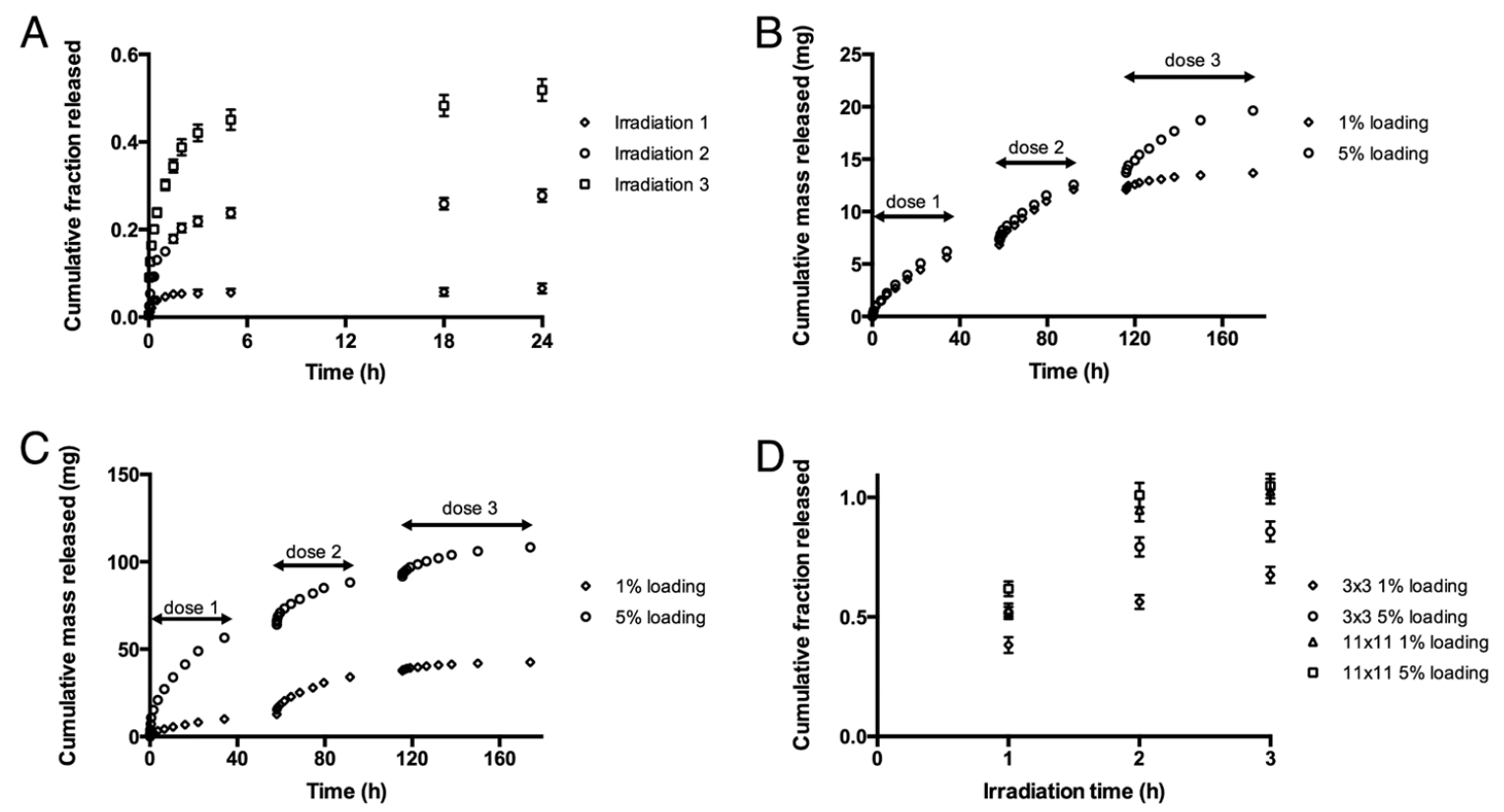

Figure 6. Cumulative fractional release profiles of ibuprofen from $3 \times 3 \mathrm{MN}$ array loaded with the light responsive conjugate, after successive periods of irradiations at $365 \mathrm{~nm}$ for 1 hour (A). 
Data are shown as mean \pm standard deviation of six replicates. Ibuprofen release from $3 \times 3 \mathrm{MN}$ array with release triggered by 3 cycles of exposure to light for 1 hour (B). Ibuprofen release from $11 x 11 \mathrm{MN}$ array with release triggered by 3 cycles of exposure to light for 1 hour (C). Total cumulative fraction of ibuprofen released from $3 \times 3$ and $11 \times 11$ arrays after successive periods of exposure to light (D). Data are shown as mean \pm standard deviation of six replicates.

\section{Discussion}

The capability to control the quantity, location and time of drug dosing is one of the main objectives in the design of drug delivery systems (37). For these purposes systems responsive to different stimulus, such as temperature, $\mathrm{pH}$ or light among others have been prepared (3841). A light triggered $\mathrm{MN}$ drug delivery system have been designed and successfully tested in vitro for the release of a clinical relevant model drug: ibuprofen. This systems combines the advantages of $\mathrm{MN}$ transdermal delivery systems with a light-controlled drug liberation reaction allowing a high level of control for the dose, the timing of the release process, and its location.

Ibuprofen was selected as a model drug for this study. It was conjugated with 3,5dimethoxybenzoin to form a light responsible compound. This type of conjugate has been previously synthetized and tested using different model molecules such as acetyl salicylic acid, ibuprofen, and ketoprofen (29). When irradiated with light of specific wavelength the conjugate is broken yielding the free drug and 2-phenyl-5,7-dimethoxybenzofuran (Figure 1B) $(29,30$, 32). The ibuprofen conjugate was successfully loaded in pHEMA hydrogels crosslinked using EGDMA. Nevertheless, prior to the incorporation of the conjugate inside the hydrogel matrix the optimal composition of HEMA and EGDMA for MN preparation was selected. The results suggested that the use of a lower amount of EGDMA (1\%) leads to the formation of more homogenous distribution of needle length in the array (see supporting information Figure S1). 
Therefore this composition was selected over the one containing 5\% of EGDMA. Additionally the swelling kinetics of this type of hydrogel was evaluated (Figure 3). The swelling process of this type of material requires more than 24 hours to reach maximum swelling. The swelling process for this type of material is slower in comparison to other materials used for the preparation of hydrogel-forming MN arrays such as Gantrez ${ }^{\circledR}$ AN-139 or Gantrez ${ }^{\circledR}$ S-97 that are able to reach maximum swelling degrees in less than 24 hours $(20,42)$. Moreover, the maximum amount of water that pHEMA hydrogels are able to uptake is substantially smaller than the previously described materials. The pHEMA hydrogel shows maximum swelling degrees of around $50 \%$ while for Gantrez ${ }^{\circledR}$ hydrogels the values are higher than $1000 \%$ after 24h $(20,42)$. The lower swelling degree combined with the slower swelling process makes this type of material more suitable for the production of prolonged drug delivery systems. Besides, the crosslinking time required to prepare pHEMA MN arrays is shorter than for Gantrez ${ }^{\circledR}$ ones $\left(2 \mathrm{~h}\right.$ at $90^{\circ} \mathrm{C}$ vs. $24 \mathrm{~h}$ at $\left.80^{\circ} \mathrm{C}\right)$. This process can be accelerated by using alternative heating sources such as microwave radiation (42). The optimization of the crosslinking time will be mandatory for the development of an industrial manufacturing process.

The next step was the incorporation of the ibuprofen conjugate in the pHEMA hydrogel matrices. The conjugate was incorporated in the solution containing HEMA monomer, EGDMA and the initiator. After the polymerization reaction, the presence of the conjugate was confirmed using Raman spectroscopy (Figure 4). The conjugate was attached to the polymer matrix through non-covalent interactions and consequently immobilized until the covalent ester that bound ibuprofen with the 3,5-dimethoxybenzoin was broken (43). The incorporation of the conjugate has no statistical significant effect on the mechanical properties of the MN arrays (Figure 5). 
Finally, MN arrays loaded with the light responsible conjugate were tested in vitro for transdermal light-triggered delivery of ibuprofen. The experiment was carried out using Franz Cells and Silescol ${ }^{\circledR}$ membrane as skin simulant. The reason for the use of the Silescol membrane was that the experiment takes several days to be complete and the integrity of excised skin during this time will be compromised. As can be seen in Figure 5, the irradiation of the MN arrays with $365 \mathrm{~nm}$ light triggers the release of ibuprofen. This process can be repeated at least three times in a consecutive way. The amount of ibuprofen released can be tailored by modifying the number of needles in the array, and the concentration of the drug in the polymeric matrix. Additionally the system allows the release of ibuprofen during prolonged periods of time (up to $160 \mathrm{~h}$ ). Additionally it is important to note that despite of the fact that the conjugate is not covalently bound to the polymer matrix there is no significant release from pHEMA matrices of the other major product obtained after irradiation of the conjugate (2phenyl-5,7-dimethoxybenzofuran) (Figure 1B) due mainly to its hydrophobicity (32). Nevertheless, in future studies this fact should be evaluated deeply in order to ascertain the safety of the device.

It is important to notice that UV radiation is shown to be the major etiologic agent in the development of skin cancers (44). Therefore this system cannot be used directly into patients in the way it is described here. The work presented here is a probe of concept and a modified version of the system should be used. Based on our previous research on hydrogel forming MN arrays we propose a hydrogel-forming $\mathrm{MN}$ array system $(16,20)$ containing a backing layer made with the material described in this work. Between the MN array and the backing layer a porous layer of a material that blocks UV radiation should be included. Therefore radiation can be applied to the system without reaching the skin surface. 
Triggerable systems such as the system presented here facilitate multiple drug dosages with a single administration. This type of delivery system is of great interest especially for the treatment of pain (45). A good example of this situation are cancer patients that often suffer from various levels of pain as symptom of the cancer or as side effect of the cancer treatment. To the date only a few authors have dealt with the combination of MN arrays and stimuliresponsive systems (26-28). Huang et al. developed a biochip for real-time measurement of glucose concentration and automatic insulin injection (28). This system was based on electronic systems rather than in stimuli-responsible materials. Recently, Chen et al. developed a MN system loaded with silica-coated lanthanum hexaboride nanoparticles that are capable to release a model molecule (Rhodamine 6G) on demand when the array was irradiated with near infrared radiation (26). The MN array was made of polycaprolactone. When the system was irradiated with infrared radiation, the presence of light-sensitive nanostructures caused a temperature increase of the array. This temperature increase leads to microneedle melting and enabling drug release. After 132 minutes and multiple infrared stimulated release cycles the system was able to release up to $80 \%$ of its cargo. The system described in the present paper was able to release ibuprofen during longer periods of time (Figure 6) making our system more appealing for long term drug administration.

\section{Conclusion}

A light-responsive MN drug delivery system has been designed and successfully tested in vitro for the release of a model drug, ibuprofen. The coupling of the application of light to the release of a predictable dose of drug has been demonstrated. The selected polymer for MN fabrication, pHEMA crosslinked with EGDMA, presented good mechanical properties and could be used to form MN arrays successfully using a micromolding technique. This technology has considerable potential for use in situations where "on-demand" drug delivery is required, with 
patient- or physician-controlled analgesia an obvious example. Our next steps will be in vivo studies aimed at ascertaining the efficacy of the system in a suitable animal model. Due to the potentially harmful effect of UV radiation on the skin, the system will be modified before its application in vivo, perhaps by including the drug and light-sensitive conjugate in the baseplate and having the needles protrude through an opaque barrier membrane into the skin. Moreover, as we take the technology forwards, we will also consider optimization of the crosslinking time using microwave radiation and the minimising the potential for release of any free 2-phenyl5,7-dimethoxybenzofuran from the array into skin following irradiation.

\section{Acknowledgements}

We acknowledge funding support from the Engineering and Physical Sciences Research Council (EPSRC) grant number EP/H012249/1. The microneedles aspects of this study were supported by BBSRC grant numbers BB/FOF/287 and BB/E020534/1. 


\section{Supporting Information}

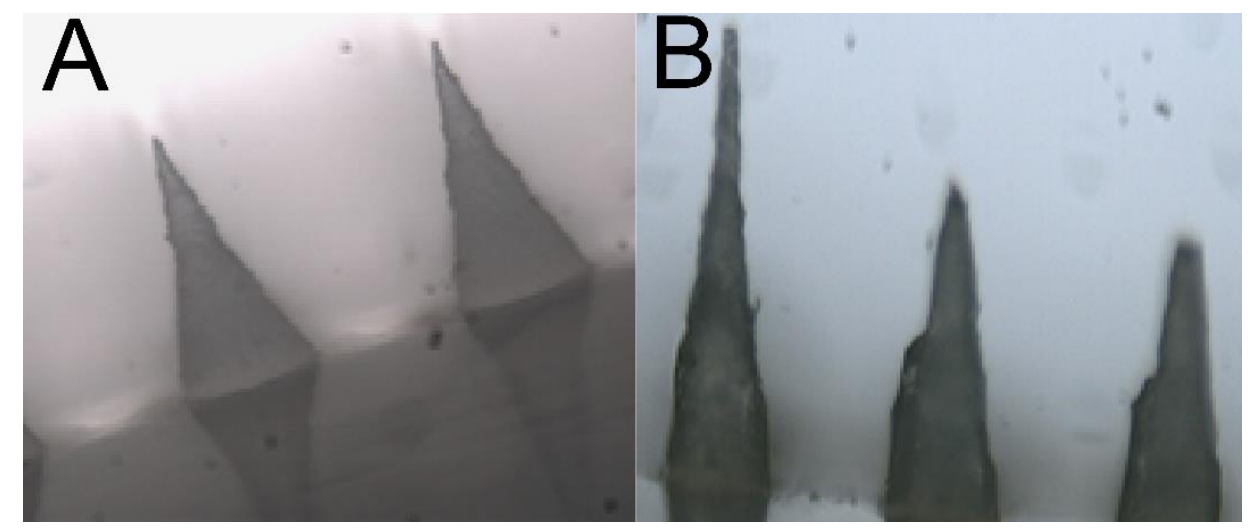

Figure S1. Morphology of microneedles prepared from the different PHEMA formulations: 1\% EGDMA, height $425.07 \pm 2.82 \mu \mathrm{m}$ and width $313.25 \pm 1.23 \mu \mathrm{m}(\mathrm{A}) ; 5 \%$ EGDMA, height $425.00 \pm 12.34 \mu \mathrm{m}$ and width $323.00 \pm 14.53 \mu \mathrm{m}(\mathrm{B})$. Data are shown as means \pm standard deviation of eight replicates.
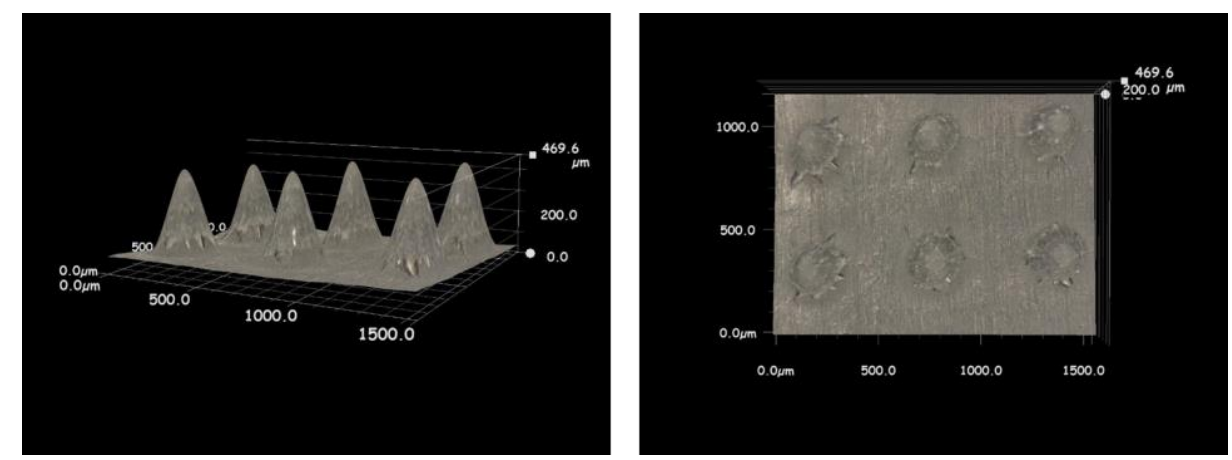

Figure S2. 3D reconstruction of 6 needles from 11x11 pHEMA MN array 
Table S1. Influence of the incorporation of the light responsive conjugate on the bulk mechanical properties of the hydrogels.

\begin{tabular}{lllll}
\hline Sample & UTS $(\mathrm{MPa})$ & Young's & Modulus $\%$ & Elongation at \\
& & $(\mathrm{GPa})$ & break \\
\hline pHEMA & & $0.40 \pm 0.09$ & $0.72 \pm 0.06$ & $154.0 \pm 16.8$ \\
pHEMA $1 \%$ light & $0.37 \pm 0.13$ & $1.13 \pm 0.21$ & $155.5 \pm 8.9$ \\
responsive conjugate & & & \\
pHEMA $5 \%$ light & $0.32 \pm 0.10$ & $1.42 \pm 0.08$ & $162.5 \pm 7.3$ \\
responsive conjugate & & &
\end{tabular}

References

1. Donnelly, R.F.; Singh, T.R.R.; Morrow, D.I.J.; Woolfson, A.D. Microneedle-mediated Transdermal and Intradermal Drug Delivery. Wiley: 2012;

2. Singh, T.R.R.; Garland, M.J.; Cassidy, C.M.; Migalska, K.; Demir, Y.K.; Abdelghany, S.; Ryan, E.; Woolfson, A.D.; Donnelly, R.F.; Singh, T.R.R. Microporation techniques for enhanced delivery of therapeutic agents. Recent Pat. Drug. Deliv. Formul. 2010, 4, 1-17.

3. Prausnitz, M.R.; Mitragotri, S.; Langer, R. Current status and future potential of transdermal drug delivery. Nat Rev Drug Discov 2004, 3, 115-124.

4. Kim, Y.C.; Park, J.H.; Prausnitz, M.R. Microneedles for drug and vaccine delivery. $A d v$. Drug Deliv. Rev. 2012, 64, 1547-1568.

5. Prausnitz, M.R. Microneedles for transdermal drug delivery. Adv. Drug Deliv. Rev. 2004, 56, 581-587.

6. Prausnitz, M.R. and Langer, R. Transdermal drug delivery. Nat. Biotechnol. 2008, 26, 1261-1268.

7. Birchall, J.C. Microneedle array technology: the time is right but is the science ready? Expert Rev. Med. Devices. 2006, 3, 1-4.

8. Coulman, S.; Allender, C.; Birchall, J. Microneedles and other physical methods for overcoming the stratum corneum barrier for cutaneous gene therapy. Crit. Rev. Ther. Drug. 2006, 23, 205-258. 
9. Henry, S.; McAllister, D.V.; Allen, M.G.; Prausnitz, M.R. Microfabricated microneedles: a novel approach to transdermal drug delivery. J. Pharm. Sci. 1998, 87, 922-925.

10. Pierre, M.B. and Rossetti, F.C. Microneedle-based drug delivery systems for transdermal route. Curr. Drug Targets 2014, 15, 281-291.

11. Tuan-Mahmood, T.M.; McCrudden, M.T.; Torrisi, B.M.; McAlister, E.; Garland, M.J.; Singh, T.R.; Donnelly, R.F. Microneedles for intradermal and transdermal drug delivery. Eur. J. Pharm. Sci. 2013, 50, 623-637.

12. Liu, S.; Jin, M.N.; Quan, Y.S.; Kamiyama, F.; Katsumi, H.; Sakane, T.; Yamamoto, A. The development and characteristics of novel microneedle arrays fabricated from hyaluronic acid, and their application in the transdermal delivery of insulin. J. Control. Release 2012, $161,933-941$.

13. Matsuo, K.; Yokota, Y.; Zhai, Y.; Quan, Y.S.; Kamiyama, F.; Mukai, Y.; Okada, N.; Nakagawa, S. A low-invasive and effective transcutaneous immunization system using a novel dissolving microneedle array for soluble and particulate antigens. J. Control. Release 2012, 161, 10-17.

14. Naito, S.; Ito, Y.; Kiyohara, T.; Kataoka, M.; Ochiai, M.; Takada, K. Antigen-loaded dissolving microneedle array as a novel tool for percutaneous vaccination. Vaccine 2012, 30, 1191-1197.

15. Hong, X.; Wu, Z.; Chen, L.; Wu, F.; Wei, L.; Yuan, W. Hydrogel Microneedle Arrays for Transdermal Drug Delivery. Nano-Micro Lett. 2014, 6, 191-199.

16. Donnelly, R.F.; Singh, T.R.R.; Garland, M.J.; Migalska, K.; Majithiya, R.; McCrudden, C.M.; Kole, P.L.; Mahmood, T.M.T.; McCarthy, H.O.; Woolfson, A.D. Hydrogel-Forming Microneedle Arrays for Enhanced Transdermal Drug Delivery. Adv. Funct. Mater. 2012, 22, 4879-4890.

17. Kim, M.; Jung, B.; Park, J.H. Hydrogel swelling as a trigger to release biodegradable polymer microneedles in skin. Biomaterials 2012, 33, 668-678.

18. Donnelly, R.F.; Singh, T.R.; Alkilani, A.Z.; McCrudden, M.T.; O'Neill, S.; O'Mahony, C.; Armstrong, K.; McLoone, N.; Kole, P.; Woolfson, A.D. Hydrogel-forming microneedle arrays exhibit antimicrobial properties: potential for enhanced patient safety. Int. J. Pharm. 2013, 451, 76-91.

19. Donnelly, R.F.; Morrow, D.I.; McCrudden, M.T.; Alkilani, A.Z.; Vicente-Pérez, E.M.; O'Mahony, C.; González-Vázquez, P.; McCarron, P.A.; Woolfson, A.D. Hydrogel-forming and dissolving microneedles for enhanced delivery of photosensitizers and precursors. Photochem. Photobiol. 2014, 90, 641-647.

20. Donnelly, R.F.; McCrudden, M.T.C.; Zaid Alkilani, A.; Larrañeta, E.; McAlister, E.; Courtenay, A.J.; Kearney, M.; Singh, T.R.R.; McCarthy, H.O.; Kett, V.L.; Caffarel-Salvador, E.; Al-Zahrani, S.; Woolfson, A.D. Hydrogel-Forming Microneedles Prepared from "Super 
Swelling"• Polymers Combined with Lyophilised Wafers for Transdermal Drug Delivery. PLOS ONE 2014, 9, e111547.

21. Garland, M.J.; Caffarel-Salvador, E.; Migalska, K.; Woolfson, A.D.; Donnelly, R.F. Dissolving polymeric microneedle arrays for electrically assisted transdermal drug delivery. J. Control. Release 2012, 159, 52-59.

22. Pawar, K.R.; Smith, F.; Kolli, C.S.; Babu, R.J. Effect of lipophilicity on microneedlemediated iontophoretic transdermal delivery across human skin in vitro. J. Pharm. Sci. 2013, 102, 3784-3791.

23. Wing, D.; Prausnitz, M.R.; Buono, M.J. Skin pretreatment with microneedles prior to pilocarpine iontophoresis increases sweat production. Clin. Physiol. Funct. Imaging 2013, 33, 436-440.

24. Singh, N.D. and Banga, A.K. Controlled delivery of ropinirole hydrochloride through skin using modulated iontophoresis and microneedles. J. Drug Target. 2013, 21, 354-366.

25. Vemulapalli, V.; Bai, Y.; Kalluri, H.; Herwadkar, A.; Kim, H.; Davis, S.P.; Friden, P.M.; Banga, A.K. In vivo iontophoretic delivery of salmon calcitonin across microporated skin. $J$. Pharm. Sci. 2012, 101, 2861-2869.

26. Chen, M.C.; Ling, M.H.; Wang, K.W.; Lin, Z.W.; Lai, B.H.; Chen, D.H. Near-infrared light-responsive composite microneedles for on-demand transdermal drug delivery. Biomacromolecules 2015, 16, 1598-1607.

27. Cahill, E.M. and O'Cearbhaill, E.D. Toward Biofunctional Microneedles for Stimulus Responsive Drug Delivery. Bioconjug. Chem. 0, 0, nu.

28. Huang, C.J.; Chen, Y.H.; Wang, C.H.; Chou, T.C.; Lee, G.B. Integrated microfluidic systems for automatic glucose sensing and insulin injection. Sensors Actuators B: Chem. 2007, 122, 461-468.

29. McCoy, C.P.; Rooney, C.; Edwards, C.R.; Jones, D.S.; Gorman, S.P. Light-triggered molecule-scale drug dosing devices. J. Am. Chem. Soc. 2007, 129, 9572.

30. McCoy, C.P.; Rooney, C.; Jones, D.S.; Gorman, S.P.; Nieuwenhuyzen, M. Rational design of a dual-mode optical and chemical prodrug. Pharm. Res. 2007, 24, 194-200.

31. Donnelly, R.F.; Majithiya, R.; Singh, T.R.; Morrow, D.I.; Garland, M.J.; Demir, Y.K.; Migalska, K.; Ryan, E.; Gillen, D.; Scott, C.J.; Woolfson, A.D. Design, optimization and characterisation of polymeric microneedle arrays prepared by a novel laser-based micromoulding technique. Pharm. Res. 2011, 28, 41-57.

32. Rooney, C.; Hayes, G.; McCoy, C.P. Photolytic release of ibuprofen from a 3,5dimethoxybenzoin ester within a p(HEMA-co-MMA) polymer matrix. J. Pharm. Pharmacol. 2003, 55, S43. 
33. Ren, Y.; Matsushita, A.; Matsukawa, K.; Inoue, H.; Minami, Y.; Noda, I.; Ozaki, Y. Twodimensional Fourier-transform-Raman and near-infrared correlation spectroscopy studies of poly(methyl methacrylate) blends. Vib. Spectrosc. 2000, 23, 207-218.

34. Lutton, R.E.M.; Moore, J.; Larrañeta, E.; Ligett, S.; Woolfson, A.D.; Donnelly, R.F. Microneedle characterisation: the need for universal acceptance criteria and GMP specifications when moving towards commercialisation. Drug Deliv. Transl. Res. 2015, 1-19.

35. Larrañeta, E.; Moore, J.; Vicente-Pérez, E.M.; González-Vázquez, P.; Lutton, R.; Woolfson, A.D.; Donnelly, R.F. A proposed model membrane and test method for microneedle insertion studies. Int. J. Pharm. 2014, 472, 65-73.

36. Lutton, R.E.M.; Larrañeta, E.; Kearney, M.C.; Boyd, P.; Woolfson, A.D.; Donnelly, R.F. A novel scalable manufacturing process for the production of hydrogel-forming microneedle arrays. Int. J. Pharm. 2015, 494, 417-429.

37. Langer, R. Drug delivery. Drugs on target. Science 2001, 293, 58-59.

38. Gillies, E.R. and Fréchet, J.M.J. Development of acid-sensitive copolymer micelles for drug delivery. Pure Appl. Chem. 2004, 76, 1295-1307.

39. Moreno, E.; Schwartz, J.; Larrañeta, E.; Nguewa, P.A.; Sanmartín, C.; Agüeros, M.; Irache, J.M.; Espuelas, S. Thermosensitive hydrogels of poly(methyl vinyl ether-co-maleic anhydride) - Pluronic(®) F127 copolymers for controlled protein release. Int. J. Pharm. 2014, $459,1-9$.

40. Sershen, S.R.; Mensing, G.A.; Ng, M.; Halas, N.J.; Beebe, D.J.; West, J.L. Independent Optical Control of Microfluidic Valves Formed from Optomechanically Responsive Nanocomposite Hydrogels. Adv. Mater. 2005, 17, 1366.

41. Li, S.K. and D'Emanuele, A. On-off transport through a thermoresponsive hydrogel composite membrane. J. Control. Release 2001, 75, 55-67.

42. Larrañeta, E.; Lutton, R.E.M.; Brady, A.J.; Vicente-Pérez, E.M.; Woolfson, A.D.; Thakur, R.R.S.; Donnelly, R.F. Microwave-Assisted Preparation of Hydrogel-Forming Microneedle Arrays for Transdermal Drug Delivery Applications. Macromol. Mater. Eng. 2015, 300, 586-595.

43. McCoy, C.P.; Gorman, S.P.; Jones, D.S. Drug delivery composition. 2011, WO2009147372.

44. Narayanan, D.L.; Saladi, R.N.; Fox, J.L. Review: Ultraviolet radiation and skin cancer. Int. J. Dermatol. 2010, 49, 978-986.

45. Timko, B.P.; Arruebo, M.; Shankarappa, S.A.; McAlvin, J.B.; Okonkwo, O.S.; Mizrahi, B.; Stefanescu, C.F.; Gomez, L.; Zhu, J.; Zhu, A.; Santamaria, J.; Langer, R.; Kohane, D.S. Near-infrared-actuated devices for remotely controlled drug delivery. Proc. Natl. Acad. Sci. U. S. A. 2014, 111, 1349-1354. 